\title{
The Intellectual Persuasion in the Twenty-First Century: A Conversation With Peter K. Bol.
}

\section{Citation}

Yao, Ping, and Peter K Bol. 2012. The intellectual persuasion in the twenty-first century: a conversation with Peter K. Bol. The Chinese Historical Review 19, no. 2: 150-161.

\section{Published Version}

doi:10.1179/12Z.0000000008

\section{Permanent link}

http://nrs.harvard.edu/urn-3:HUL.InstRepos:11213548

\section{Terms of Use}

This article was downloaded from Harvard University's DASH repository, and is made available under the terms and conditions applicable to Other Posted Material, as set forth at http:// nrs.harvard.edu/urn-3:HUL.InstRepos:dash.current.terms-of-use\#LAA

\section{Share Your Story}

The Harvard community has made this article openly available.

Please share how this access benefits you. Submit a story.

Accessibility 


\title{
THE INTELLECTUAL PERSUASION IN THE TWENTY-FIRST CENTURY: A CONVERSATION WITH PETER K. BOL
}

\author{
Ping Yao
}

Peter K. Bol is the Charles H. Carswell Professor of East Asian Languages and Civilizations at Harvard University. A leading scholar in the field of Chinese intellectual history, the muchpublished Professor Bol has long been an active figure in academic conferences and research collaborations. Professor Bol's influential works on Neo-Confucianism, especially the monograph, "This Culture of Ours": Intellectual Transitions in T'ang and Sung China ${ }^{1}$ and his recent book, Neo-Confucianism in History $^{2}$, present a compelling delineation of the transformation and magnification of intellectuals' roles from the $7^{\text {th }}$ century to the $17^{\text {th }}$ century. Professor Bol is also a distinguished Harvard faculty member, being its first director of the Center for Geographic Analysis, first director of the China Biographical Database project, and department chair during 1997-2002. He won the prestigious honor of college professor, in recognition of his dedication to teaching.

I first met Professor Bol in the spring of 1997 when I participated in a symposium he organized for graduate students in the field of premodern China. During the 2008-09 academic year, I was a visiting professor at Harvard Divinity School and had the opportunity to tour his Center for Geographic Analysis and meet with him from time to time to discuss the CBDB project. I also visited his class and interacted with his students. I sensed that Professor Bol's vision and passion as a humanist and his dedication to education are very similar to those of Neo-Confucians of the Song-Yuan-Ming eras, save for his acute interest in global politics and, especially, the state of affairs in the U.S. and China.

Professor Bol graciously agreed my request for email interviews, to be featured in CHR's continuing series, and here is what he had to say.

1. During your presentation at the 2011 AAS meeting, you briefly discussed your training as a sinologist. I couldn't help but wonder what made you so interested in sinology?

I did not begin with an interest in sinology - which I take to mean the study of everything about China using the scholarly apparatus that has developed in traditional Chinese scholarship. I was interested in modern Chinese and American politics. At that time the U.S. did not recognize Beijing and the PRC as the legitimate government, which seemed to me (since I was brought up somewhat left-wing) to be committing ourselves to ignorance. So I decided I would learn more about China, but I was really interested in modern China. It so happened that I was studying at the Sinological Institute in Leiden, the year after graduating from high school. The professor invited me to continue on (instead of going to Columbia), and just at that moment the Cultural Revolution began to break out. This made contemporary China unattractive (at that point I still wanted to admire a country and China was not admirable), but I was learning more about history

\footnotetext{
${ }^{1}$ Peter K. Bol, "This Culture of Ours": Intellectual Transitions in T'ang and Sung China. Stanford: Stanford University Press, 1992.

${ }^{2}$ Bol, Neo-Confucianism in History. Cambridge: Harvard University Asia Center, 2008.
} 
and that was exciting because it was so new to me. I ended up staying in Leiden through my MA, with a $31 / 2$ year stint in Taiwan studying the Confucian Classics, and thus received a very traditional sinological education.

2. You have adopted a broad social science approach in your scholarship. Would you consider sinology training an indispensible part of being a China historian?

It may appear that way now, but I expect serious social science historians would be rather surprised to see me included among them. I would say that my real intellectual development out of sinology was the move into intellectual history, understood not as the study of philosophy per se but as an inquiry into how and why shared values changed over time. I was not at all sympathetic to historical sociology as a graduate student at Princeton, although one of the people I spent a lot of time talking to and arguing with besides my advisor Willard Peterson was the sociologist Marion Levy. What makes me appear to be in the social science camp, I suspect, is my interest in dealing with large amounts of data through geographic information systems, social network analysis, and databases. In these endeavors I am very much in debt to, but also carrying a burden for, the later Robert Hartwell, who was truly a social science historian and not a sinologist. Ultimately I guess I am a humanist historian.

As for whether sinological training is necessary, this is a question that has started to come up a lot when I discuss the computational projects (CHGIS and CBDB) that I am involved with. I fear I have arrived at an answer that disappoints some: I do not see it as necessary. Is it a good thing? Yes, it will broaden you, it will enable you to work with more material on your own - but it is not necessary, no more than the study of Greek and Latin is necessary to the study of China (still a requirement for humanities students in Leiden when I was a student; although I only had some Latin). I think we should accept, as we did with political science and economics, that it is possible to study a country without trying to become expert in its traditions of scholarship. New questions and methods emerge, and with limited time one has to make choices. This does not, however, make traditional studies (like intellectual history or literature) irrelevant or less in need of smart students, it just means there are more options available to those with an interest in China. We all benefit from that.

3. You have spent tremendous amounts of time mentoring your students and are very passionate about teaching. What is your philosophy of being a teacher? How do you balance your teaching and research?

I can't say that I do a good job of balancing. Students, current students at least, have first call on my time. They have schedules to meet and must make progress toward their degrees if they are to get on with their lives. I do not think I have a philosophy of teaching, although I do think I have learned things that are worth others understanding so I try to explain as best I can.

4. You have been leading the China Biographical Database Project for the past five years. How did you get involved? Why is this project so dear to you? 
The CBDB website has a history of the project and how Harvard got involved. ${ }^{3}$ It interests me from two angles. As an intellectual historian I want to understand how new movements spread. CBDB offers data to track relations, such as teacher-student and friendship relations, to see where certain kinds of books were being written and who was writing them, to explore kinship connections, etc. In my work on local cultural history, which is focused on Wuzhou 丞州, (later Jinhuafu 金華府), I needed to see whether phenomena similar to what I found in Jinhua were happening elsewhere. It turns out CBDB is very useful for this purpose, precisely because I am interested in literati, the people who are most likely to end up in the historical record.

5. What is your vision of the end product for CBDB? What is your estimate of number of the entries? What types of sources will be included? What types of format will be available to users?

At the moment (May 2011) we have data on 112,000 people, mainly Tang through Qing. The amount we have on a given individual varies greatly, depending on the sources we are mining. Thus we may have 1000 social relationships for a Zhu Xi 朱喜 but may know little more than the name and a single kinship tie of another person. There are millions of data points in the database. We begin from biographical records - this is not yet a prosopographical database that aims to collect every person name that appears in the historical record. We are very weak on the Ming dynasty at the moment and will take steps to rectify this during the next three years. Ultimately I expect the database to have something between 250,000 and 500,000 figures in it.

We see $\mathrm{CBDB}$ as operating in an online environment where there are many sources of information - such as text databases - which CBDB should be interoperable with but will not seek to replace. The role of CBDB is to be a database of biographical information that supports historical analysis. We want to support other digital online projects in pursuing their particular interests by making it possible for their users to turn to CBDB for extensive biographical information. Let me give you an example. The Ming Qing Women's Writings Database, led by Prof. Grace Fong of McGill University, has texts of women's writings and some information of the social and kin associations of women. In the future MQWW will be able to jump directly into CBDB online to get more extensive, and better organized data on family, associations, careers etc.; when CBDB users come across someone whose writings are dealt with in MQWW they will jump to that. We have such collaborative arrangements with a number of online databases, giving us increasing amounts of data for Tang through Qing. But we are also establishing collaborations with individual researchers who in the course of their research have amassed very significant amounts of biographical data and would like to see it preserved in CBDB, both for their own use and because they do not want their raw data to simply disappear. Because CBDB codes almost all of its data, collaboration can become a complicated business; we are actively trying to figure out how to lessen the burdens that are involved in collaboration and sharing.

Another way in which we are building the database is through our work with computer scientists on text mining using such procedures as "named entity recognition," "regular expressions," and some probabilistic text modeling techniques. This has led to very important advances in our ability to capture biographical data in texts with a high degree of "recall" and "precision" (these

\footnotetext{
${ }^{3}$ http://isites.harvard.edu/icb/icb.do?keyword=k16229
} 
are technical terms). Thanks to Institute of History and Philology at Academia Sinica (Zhongyang yanjiu yuan lishi yuyan yanjiu 中央研究院歷史語言研究所) we have access to the best digital versions yet made of historical texts. In addition our editorial board at the Center for the Study of Ancient Chinese History (Zhongguo gudaishi yanjiu zhongxin 中國古代史研究中 心) at Peking University reviews and corrects the database entries. It is really something to see a program rip through 25,000 biographies at once and collect all the data one wants.

6. In its short existence, CBDB has benefited many scholars in the field of Chinese history. Would you give us some of the best examples of such scholarship? In your opinion, what are some of the potentials that have yet to be fully utilized?

In fact until this year we have been rather quiet about it, because we felt that we did not have enough data in the system for it to be really useful (we began with data on 20,000 individuals). Now after successful three day workshops in Beijing, Taibei, Kyoto, Tokyo, and at various places in the U.S. I expect to see more and more use of some of the functions and the contents of the system. Prof. Michael Fuller at UC Irvine has kept improving the functionalities of the standalone data base and Tudor Technical Services in Taibei has been maintaining the online systems.

How people have been using it is hard for me to say because the database can be freely used. It can be downloaded without registration. Thus the only use cases I know are people with whom I have direct contact, and of course my own use of the database. Our goal has been to construct the database so that it would be useful in many different kinds of inquiry. Both the stand-alone database and the online database include many kinds of queries that have been preprogrammed so you do not have to understand much about databases (you need to understand that although the query appears straightforward it often involves joining many different tables together). On the other hand if you know something about joining tables in a relational database query you will be able to ask all sorts of other questions of your own devising.

Perhaps the easiest thing is to tell you about the examples we use in workshops and demonstrations without telling you what the results are. I hope your readers will investigate for themselves. For example:

1) Look at age at death (for males and females) over time and space. What does this tell us about the likely expectations of elites in planning their lives in the past?

2) Consider where the elite came from and how they entered office. How does this change over time? Which areas are represented and which not? Are different modes of entry (e.g. yin 蔭 privilege versus examinations) spatially differentiated?

3) Consider the kinship networks of examination degree holders from a certain place. To what extent are the people from given place related to each other? How does this change over time.

4) Examine the social networks of people who became nationally famous or gained high office. What kinds of people are found within those networks and where do they come from?

5) Examine to what extent did the leaders of the civil administration form an oligarchy. See who the incumbents were in leading offices, what the positions of the ancestors and descendants were, and the degree to which they intermarried. 
7. In what ways do you expect CBDB to change the field of China history? Has it had an impact already?

First, I hope that it will make it easier for people to think comparatively across regions. For many questions, treating all of China as a unit of analysis is not as good as looking at regions and comparing them. After all, one region of China maybe larger and more populous than many countries. With CBDB we can locate large amounts of biographical data in the landscape; when we do that with regard to almost any question the differences become apparent. If there are differences we need to account for them. Second, I hope it will help scholars go beyond the historical anecdote as evidence for historical phenomena and instead quickly and easily draw on thousands of examples rather than a few. CBDB does give a reliable sampling of the elite life histories. However, it is a database rather than a dictionary and it does contain errors. But, if we have one thousand examples does it matter if ten are wrong? Third, I hope it will help us see the lateral connections between people and encourage us to use those connections as a way of accounting for historical change, rather than supposing that government activity alone is the agent of change.

8. You are the founding director of Chinese Historical Geographic Information System (CHGIS) at Harvard. Would you give us an overview of the project and its importance?

CHGIS project started about ten years ago and has received funding from the Henry R. Luce Foundation and the National Endowment for the Humanities. We are partner with Fudan University's Center for Chinese Historical Geography to establish a single, common "base" GIS. It is an internationally available and authoritative platform, free for academic use to all interested scholars, teachers and students.

Our goal is to store all changes in administrative units from the Qin Empire in $221 \mathrm{BCE}$ to the end of the imperial period (1911) and to provide users a means to add quantitative and qualitative data on society, politics, economy, and culture for particular periods and areas of interest. It will also allows users to search, compare and analyze their own data in relationship to numerous other types of data, and to test hypotheses about spatial relationships, to generate historical maps for research, teaching, and publication, or to share their data with others.

At this point the project is nearly finished (areas in Sichuan and in North China are incomplete). Fudan has finished much of what it planned to accomplish. It has also become clear that the historical record does not allow us to do a reliable time series for the Wei-Jin Nan-Bei chao period.

9. Would you give us some examples of what a historical GIS can do for research?

Since a GIS stores geographical information in an electronic database and allows the user to choose which parts of the data to display and how to display them, this means that different kinds of information can be introduced separately and then overlayed in different combinations to explore spatial relationships. For example, the administrative boundaries for a particular year can be overlayed on the topography as derived from contemporary remote sensing data. Or the locations of historic Buddhist Temples can be georeferenced using the known historical locations of towns and counties in the CHGIS database. The following figure shows two examples: on the left is the 1820 prefectural boundaries of Yunnan when combined with elevation map, and on the right the distribution and density of Buddhist Temples listed in the 1820 National Gazetteer. 




Left - 1820 Prefectural Boundaries of Yunnan when combined with elevation map

Right - distribution and density of Buddhist Temples listed in the 1820 National Gazetteer

Since GIS software includes a variety of analytic tools, it allows the users to measure distance, area, degrees of proximity, and much more. One can create maps, do statistical calculations, and generate charts. In addition, the user can add new information at will. Let me give you an actual example using CHGIS time series data. Here we have joined commercial tax quota statistics for prefectural and county seats and towns to the CHGIS records. Once the spatial data has been joined to the statistical data, we may take advantage of numerous built-in features in GIS software to produce thematic maps. 


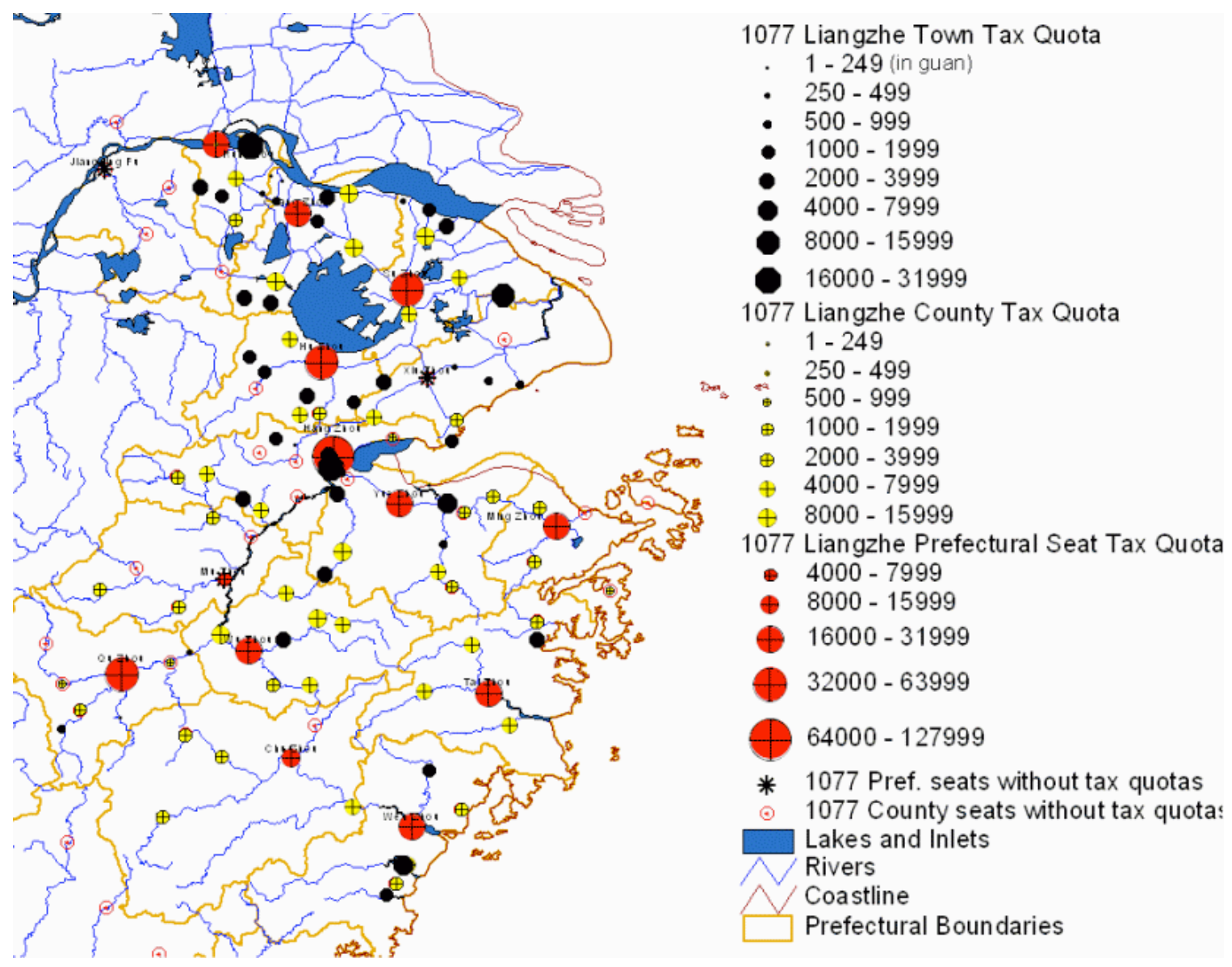

Comparison of tax quotas for Administrative Seats and Market Towns in 1077

Furthermore, an historical GIS adds the fourth dimension of time and is set up so that it can accommodate many moments in the past. It makes it possible for users to ask the question: How did the situation change over time? It allows historians to compare data that is place specific and time specific as the data changes through space and time, and to perform a thorough spatial analysis of empirical data on their own at minimal cost.

There is growing evidence that historians have begun to use GIS to go beyond mapping their data to analyze the spatial relationships in the data with ease and exactness and to see connections that earlier scholarship had missed. For example, Goeff Cunfer has been able to challenge Worster's argument that the "dust bowl" of the 1920s and 30s was the result of overplowing by combining land-use and meteorological data with dust storm records and archaeological data to show that dust storms were primarily a consequence of drought and did not result from plowing. Amy Hillier's construction of a GIS that combined real estate grading maps with the exact location of bank loans has allowed her to challenge the claim that banks refused mortgages in "red-lined" districts. These and other recent examples are collected in Past Time, Past Place: GIS for History. ${ }^{4}$

10. Your first monograph, "This Culture of Ours": Intellectual Transitions in T'ang and Sung China, illuminates the intellectual change from wenxue文學 to daoxue 道學 and links such

\footnotetext{
${ }^{4}$ Anne Kelly Knowles, ed., Past Time, Past Place: GIS for History. Redlands, CA: ESRI Press, 2002.
} 
change to the social transformation of the shi 士 class. I am sure many readers consider you an intellectual historian, but being unfamiliar with intellectual history, I appreciate the book's social history approach tremendously. Would you consider yourself a social historian as well? What is your take on social history approaches in Chinese history?

I think of myself as an intellectual historian who is interested in how and why shared values change. Once you say "shared" then you are talking about people rather than the individual thinker and in that sense it is about social groups. In fact "This Culture" really is built up through studies of leading, influential individuals. They are assumed to represent a set of choices that literati at the time had available, although the set is certainly not exhaustive. There was really only one chapter which tried to synthesize the findings of social historians to define the social context in which literati intellectuals developed their ideals and arguments and to suggest a general reason for why Daoxue Neo-Confucianism spread among the literati. I never did get around to revising my dissertation for publication-it was devoted to Su Shi 蘇軾 and his four most important followers (in other words it was the study of a group) - but it was the incubus for some of the ideas in "This Culture". I am inclined to think that the real contribution of that book was to show how wenxue could figure in thinking about China's intellectual history. At least in the U.S. this has not been welcomed by students of literature, although it seems to have struck a greater cord in China, perhaps because there the boundary between literature and thought is not as sharply drawn.

11. Your new book, Neo-Confucianism in History, analyzes the important and changing role of Neo-Confucianism in the politics, culture, and society of mid and late imperial China. I find your accounts of Neo-Confucians and their moral leadership and devotion to local communities quite inspirational. In your last paragraph of the book you seem to call upon contemporary Chinese intellectuals to do the same. Do you think they can play as a pivotal role as their counterparts did in Song-Yuan-Ming eras? In what ways?

I hope they want to. Whether in the short term they will be able to or not is not entirely up to them.

12. In the book you argue that literati of $11^{\text {th }}$ century faced a different world than that of the $8^{\text {th }}$ century in terms of foreign relations, dynamics of the North and the South, commerce and urbanization, and social fabrics, and that Neo-Confucianism was thus very much a response to such change. You also discuss some changes in family status and marriage, but do not go into great detail in terms of gender relations and gender roles. Yet, many writings blamed Neo-Confucianism for the decline of women's status. What is your take on this?

It strikes me that the person who has argued for this most extensively has in later work given us a somewhat different account. It seems to me that it is very hard to show that Neo-Confucians were trying to lower the status of women. We might ask instead what effects the kinds of things Neo-Confucians promoted could theoretically have on the status of women and whether this was borne out in practice. We might also ask whether these are ideas or more general sociopolitical ethics. Neo-Confucians stressed the importance of the family and family continuity. When this was combined with the idea of widow chastity (a parallel to a male official's serving only one 
ruler), at least for literati women, the upshot was that a widow and her dowry property should remain in the family of her first (and only) husband. Now we know that widows continued to remarry and that such models applied to the elite rather than the general population. In China it was once standard in a discussion of Neo-Confucianism to point out that Cheng Yi 程頣 thought a woman's honor was more important than her life, that rape was, as it has been called in the West, "a fate worse than death." Should both men and women value integrity more than life itself (as Mencius said)? One can disagree with that proposition, one can argue that rape does not rise to that level, and one can insist that victims of aggression should not be held responsible in this fashion. We need to keep in mind that Neo-Confucians were moralists in the first instance.

13. Several scholars describe your new book as a sequel to "This Culture of Ours". Would you care to share the direction of your upcoming projects? Will they also be centered on the NeoConfucian story?

It is indeed, although originally I was planning to do a very short and easy-to-read book about Neo-Confucianism as a position, identity, and social movement. But as the picture became more complex the book became more demanding. Since "This Culture" my main project has been a study in local cultural history from the $12^{\text {th }}$ into the $17^{\text {th }}$ century. I have published a number of articles on this but have been delayed in writing a book by projects like CHGIS and CBDB. In essence, what I have been exploring is the formation of literati culture at the local level and the interaction between local, translocal, national, and central phenomena using Wuzhou or Jinhuafu from Song through Ming as case studies. Neo-Confucianism figures in this as part of the story, but only as part of the picture. I am interested in Jinhua because in the Yuan dynasty local literati were using local identity as a means of creating a community, in Song and Yuan they were interested in ways they could take responsibility for community well-being, and in early Ming Jinhua literati played important roles in the formation of the Ming dynasty.

There are three other projects I would like to see through. One is on intellectual culture in a broad sense during the latter half of the fifteenth century, when literati were exploring alternatives to Neo-Confucian ideas but ultimately moral philosophy survived. Another is on the seventeenth century when Neo-Confucianism lost its hold on the center of intellectual life. Finally, if I am very long lived, I would like to write an intellectual biography of Zhu Xi, primarily for those outside of Chinese studies who are interested in intellectual history.

\section{What is your take on Confucius Institutes?}

I think making it easier for people outside of China to study Chinese is very important and the willingness of China to invest in this is very much to be welcomed. Why this should have the name of Confucius attached to it I am not sure, presumably when courses are offered they do not have to remain within the confines of a presumed Confucianism. But let us look at the larger question: what can the Chinese government and the private sectors do to make knowledge about China in general, not just language training, more accessible to the world. There are, I think, some important things that could be done. Digitization projects supported with government monies could be made open-access without cost, or private initiatives could be subsidized to make the cost structure more equitable. Foreign universities simply do not have endless supplies of cash for library acquisitions. Those of us who care about China studies think China is central, 
but in fact China studies are still very marginal at most U.S. institutions, where there may be only one person in China studies. If we really want to make knowledge about China more accessible, along with the sources for that knowledge, then we need to find a way to make access to Chinese resources affordable. I hope the Confucius Institute will see this as part of its mission.

15. In your opinion, what have been the major trends in American historiography on Chinese history over your career? Can you comment on them?

This is a really hard question. The rise of social history and local history have made a difference in my own work. Thinking about culture as socially constructed, deconstruction in literature, gender studies, all of these have changed the way we approach China's past. I think there have been some fundamental changes in the way we think about China's history over the last thirty years. For example, we have moved from the assumption of civilization in China as having a single point and lineage of origin to its being the result of interaction between many regional cultures; from China as a single unit of analysis to China as composed of many regions; from the idea of China as having been "isolated" to seeing it as having been a player in transnational contexts throughout its history; from seeing Chinese government as an autocracy to recognizing the complex interactions between inner court, civil administration, military power, elites, and local society; from a simplistic dichotomy between an unchanging "pre-modern" China and a "modernizing" China to an understanding of China's past as being marked by a series of great transformations, of which the modern is the latest. We tend to absorb technology into our ways of working, we keyboard rather than type, but in fact computation has altered our research environment in important ways: in our ability to search sources, to tie data together in databases, to map data, to run quantitative analyses, to build image collections, etc. Publishing has yet to catch up with what we can do on our own.

16. What is your assessment of Chinese scholarship in your field? What has changed? What's coming? What would you like to see in the future?

In the fields I am interested in - intellectual history, local history, sociocultural history - the amount that is being published today is so great that I cannot keep up, so I would not dare assess the quality of scholarship. When I began studying Chinese history the most valuable work coming out of China was not research scholarship but the preparing of critical editions of primary works, what is called guji zhengli 古籍整理. Today, there is more scholarly freedom and fewer constraints on an author's choice of topics and point of view; reading scholarship from China is very interesting. Clearly China has certain strengths that are missing in American scholarship - institutional history, for example, and economic history for many periods. I would think that writing about China's history in China is very different from writing about China in another country. The study of China's history is an international field, with significant work being produced in China, Japan, Europe, and the U.S. We need to keep thinking about how to increase communication and collaboration. 